\section{LA-UR-97 2895}

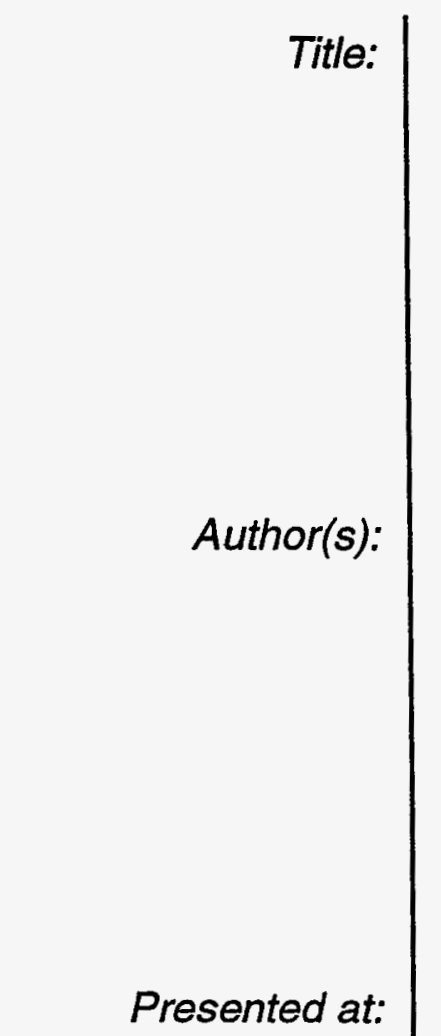

To be submitted to:

\section{CONF-970707--4}

\section{MICROSTRUCTURE OF DEPLETED URANIUM UNDER UNIAXIAL STRAIN CONDITIONS}

RECEIVED

AllG 131997

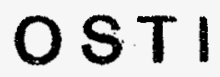

A. K. Zurek, J. D. Embury, A. Kelly, W. R. Thissell,

R. L. Gustavsen, J. E. Vorthman, and R. H. Hixson

Materials Science and Technology Division

Los Alamos National Laboratory

Los Alamos, NM 87545

Proceedings for the Shock Compression of Condensed

Matter - 1997

APS Topical Conference in Amherst MA

July 26 - August 1, 1997

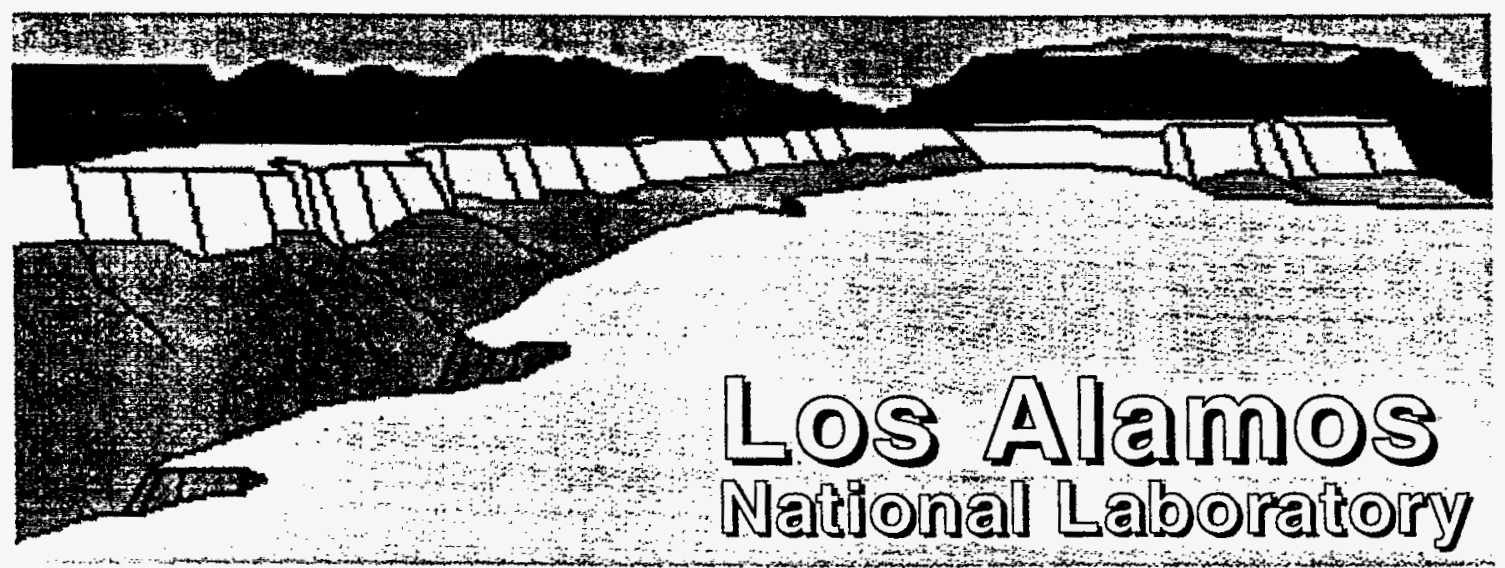

Los Alamos National Laboratory, an affirmative action/equal opportunity employer, is operated by the University of California for the U.S. Department of Energy under contract W-7405-ENG.36. By acceptance of this article the publisher recognizes that the U.S. Govermment retains a nonexclusive, royaltyfree license to publish or reproduce the published form of this contribution, or to allow others to do so, for U.S. Government purposes. The Los Alamos National Laboratory requests that the publisher identify this article as work performed under the auspices of the U.S. Department of Energy. This is a preprint of a paper intended for publication in a journal or proceedings. Beceuse changes may be made before publication, this preprint is made available with the understanding that it will not be cited or reproduced without the permission of the author. 


\section{DISCLAIMER}

This report was prepared as an account of work sponsored by an agency of the United States Government. Neither the United States Government nor any agency thereof, nor any of their employees, make any warranty, express or implied, or assumes any legal bability or responsibility for the accuracy, completeness, or usefulness of any information, apparatus, product, or process disclosed, or represents that its use would not infringe privately owned rights. Reference herein to any specific commercial product, process, or service by trade name, trademark, manufacturer, or otherwise does not necessarily constitute or imply its endorsement, recommendation, or favoring by the United States Government or any agency thereof. The views and opinions of authors expressed herein do not necessarily state or reflect those of the United States Government or any agency thereof. 


\section{DISCLAIMER}

Portions of this document may be illegible in electronic image products. Images are produced from the best available original document. 


\section{PEER REVIEW}

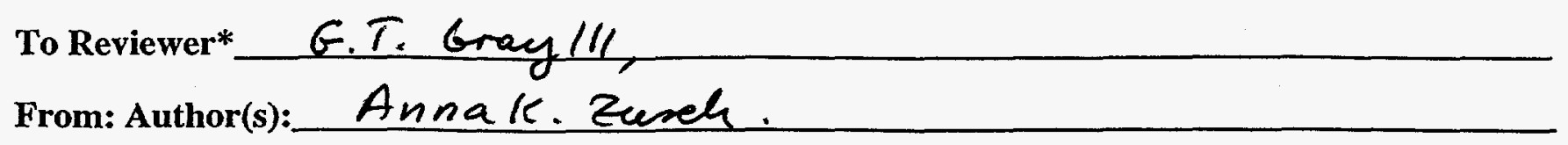

\section{Subject: Peer Review}

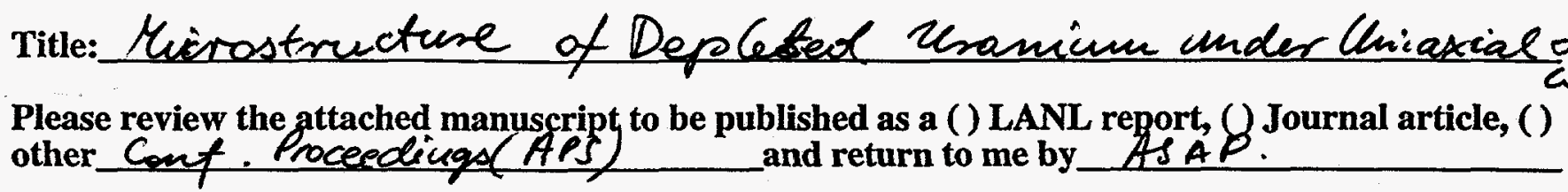

Please review this paper with as much care as you would give to a review for a high quality journal. Remember that the continued effectiveness of our peer review system is essential to maintaining the high standards that MST-5 has for its publications. Reviewing technical papers is an intellectual process that includes both subjective and objective elements. The reviewer must be objective in the sense of eliminating any personal bias he may have toward the subjective matter. At the same time the reviewer must evaluate a list of possible attributes, for the reviewer will almost always have some reactions that fall outside the scope of the guidelines given below. Nevertheless, the following list provides a minimal set of characteristics which should be evaluated.

1. Originality. Is the work sufficiently new to merit publication?

2. Significance. Is the work an important contribution to the field?

3. Completeness. The assumptions should be correct, the data valid, the scientific method sound, the conclusions adequately based on the data and theory.

4. Work of others + should be properly acknowledged.

5. Organization. The organization of the paper is extremely important of the reader is to understand the work. Ideas are most effectively communicated when there is a carefully planned and logical structure in the manuscript. The paper must be well written conform to recognize standards of literary style, and be readily understandable by engineers and scientists in the field.

6. Tables and figures Should be clear and compliment the text. The figures should be suitable for reproduction. Standard units should be used uniformly in the paper.

7. Overall clarity of the paper is extremely important; it cannot be overemphasized. A paper is written to convey ideas to the reader and this will only be achieved when the author uses the right choice of words, effective sentence structures, correct spelling and punctuation, and paragraphing. Is the research objective clearly defined? Is the objective of the work met?

Please make your comments on a separate sheet. You may also mark the manuscript. Return the comments and the manuscript to the author. If you ate satisfied that the paper is suitable of republication, initial this peer review form. This form will accompany the draft during the line management approval process through the Divisipn Tevel.

Signature to indicate approval:

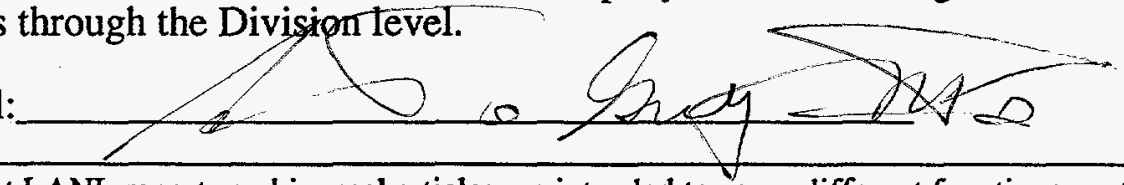

+The reviewer should recognize that LANL reports and journal articles are intended to serve different functions, so these criteria need to be applied in view of the intent of the paper.

*Two reviewers are required. They should be selected only after consultation with the section Leader. One reviewer should be outside the immediate section if possible. 
PEER REVIEW

To Reviewer* S.R. Chen

From: Author(s): Anna K. Zeres

Subject: Peer Review

Title: Microctnecture of Depleted Uranimm moler Uniaxial Srain conor.

Please review the attached manuscript to be published as a () LANL report, ( Journal article, () other. and return to me by

Please review this paper with as much care as you would give to a review for a high quality journal. Remember that the continued effectiveness of our peer review system is essential to maintaining the high standards that MST-5 has for its publications. Reviewing technical papers is an intellectual process that includes both subjective and objective elements. The reviewer must be objective in the sense of eliminating any personal bias he may have toward the subjective matter. At the same time the reviewer must evaluate a list of possible attributes, for the reviewer will almost always have some reactions that fall outside the scope of the guidelines given below. Nevertheless, the following list provides a minimal set of characteristics which should be evaluated.

1. Originality. Is the work sufficiently new to merit publication?

2. Significance. Is the work an important contribution to the field?

3. Completeness. The assumptions should be correct, the data valid, the scientific method sound, the conclusions adequately based on the data and theory.

4. Work of others + should be properly acknowledged.

5. Organization. The organization of the paper is extremely important of the reader is to understand the work. Ideas are most effectively communicated when there is a carefully planned and logical structure in the manuscript. The paper must be well written conform to recognize standards of literary style, and be readily understandable by engineers and scientists in the field.

6. Tables and figures Should be clear and compliment the text. The figures should be suitable for reproduction. Standard units should be used uniformly in the paper.

7. Overall clarity of the paper is extremely important; it cannot be overemphasized. A paper is written to convey ideas to the reader and this will only be achieved when the author uses the right choice of words, effective sentence structures, correct spelling and punctuation, and paragraphing. Is the research objective clearly defined? Is the objective of the work met?

Please make your comments on a separate sheet. You may also mark the manuscript. Return the comments and the manuscript to the author. If you ate satisfied that the paper is suitable of republication, initial this peer review form. This form will accompany the draft during the line management approval process through the Division level.

Signature to indicate approval: Sh/h-/ $\mathrm{Ch}$ 7/15/97

+The reviewer should recognize that LANL reports and journal articles are intended to serve different functions, so these criteria need to be applied in view of the intent of the paper.

*Two reviewers are required. They should be selected only after consultation with the section Leader. One reviewer should be outside the immediate section if possible. 


\title{
MICROSTRUCTURE OF DEPLETED URANIUM UNDER UNIAXIAL STRAIN CONDITIONS
}

\author{
A. K. Zurek, J. D. Embury, A. Kelly, W. R. Thissell, R. L. Gustavsen, \\ J. E. Vorthman, and R. S. Hixson
}

Los Alamos National Laboratory, Los Alamos, NM 87545

\begin{abstract}
Uranium samples of two different purities were used for spall strength measurements. Samples of depleted uranium were taken from very high purity material (38 ppm of carbon) and from material containing $280 \mathrm{ppm}$ carbon. Experimental conditions were chosen to effectively arrest the microstructural damage at two places in the development to full spall separation. Samples were soft recovered and characterized with respect to the microstructure and the form of damage. This allowed determination of the dependence of spall mechanisms on stress level, stress state, and sample purity. This information is used in developing a model to predict the mode of fracture.
\end{abstract}

\section{INTRODUCTION}

Uranium is a very high density material (19.1 $\mathrm{g} / \mathrm{cm}^{3}$ ) that is relatively strong and easily cast and formed. It is widely used in nuclear and nonnuclear applications as radiation shields or kinetic energy penetrators. The most common form of pure uranium is the U-238 isotope containing some U-235. The most commonly used is lowtemperature $\alpha$ orthorhombic phase depleted uranium. This phase is ductile, but its ductility is very dependent on processing and impurity content. The ductile-to-brittle transition of $\alpha$ uranium occurs around $0^{\circ} \mathrm{C}$, but decreasing the grain size and hydrogen content can cause it to vary. Impurities have very low solubility in uranium, and they usually form second-phase particles that may decrease macroscopic ductility. Carbon (C) forms carbide inclusions, which may decrease ductility [1] in a manner analogous to carbides in ferritic steels.

Spallation is one of many experimental configurations that can produce controlled dynamic fracture. Spallation is defined as a dynamic uniaxial strain fracture experiment. Fracture occurs during spallation due to tensile stresses generated by the interaction of two release (rarefaction) waves [2]. Spallation is a process of damage accumulation and linkage that differs drastically from fracture damage in the uniaxial tensile test by virtue of the stress state and the rate of extent of damage accumulation. In a tensile test, voids and cracks are subject to a nearly uniaxial stress tensile field; homogeneous plastic strain dominates the flow process for most of the strain history. Due to the uniaxial stress deformation field, the voids or cracks grow to form a fracture surface, and the overall change in porosity in the vicinity of failure is small, on the order of $5 \%$ [3]. In contrast, in spallation, voids or cracks are subject to extremely high, nearly isotropic, triaxial, hydrostatic stress fields, and high strain rates, which vary spatially in the sample. Voiding or crack growth dominate all stages of the damage process and produce porosity of up to about $30 \%$ at the principal spall plane. The growth rate of voids or cracks is very high, and the distribution of damage is dictated by the large gradient in stress and strain rate generated by the interaction of release waves. Porosity, void or crack formation, growth, and coalescence, therefore, 
are important variables in descriptions of spallation and the fracture criteria of the material $[2,4,5]$.

In this paper we report on microstructural damage development characterization in depleted $\alpha$ uranium deformed under spall conditions.

\section{MATERIALS AND EXPERIMENTS DESCRIPTIONS}

Depleted uranium samples containing $280 \mathrm{ppm}$ $\mathrm{C}$ were studies [6]. The as-cast material was wrought to specifications by the process of heat treatment, upset forging, re-heating, and finally hot rolling to $58 \%$ of the original thickness in four equal reduction passes. Due to this process the resulting microstructure is not uniform across the plate thickness. Large grains $(200 \mu \mathrm{m})$ dominate the center of the plate while a substantially reduced grain size (down to $40 \mu \mathrm{m}$ ) exist near the top and bottom plate surfaces. Samples were cut from the center of the plate. Similarly, the high-purity depleted uranium that contained only $38 \mathrm{ppm} \mathrm{C}$ was wrought; however, the final microstructure was uniform and consisted of equiaxed $10-\mu \mathrm{m}$ grains.

Samples were spalled and incipiently spalled using a gas gun under uniaxial strain state conditions. The spall tests were performed under nonsymmetric shock conditions; a z-cut quartz flat plate was impacted against the depleted uranium samples at a shock pressure not exceeding $5.3 \mathrm{GPa}$ for 1- $\mu$ s pulse duration. VISAR traces of the wave interactions were acquired and are described together with all other shock experimental details in a companion paper authored by R. Hixson et al. in this volume. Soft recovered samples were stored immediately in 200-proof dehydrated ethyl alcohol to prevent sample oxidation. Metallographic samples, cut through the center of the spalled sample in the direction parallel to the loading direction, were prepared for quantitative analysis [7].

\section{RESULTS AND DISCUSSION \\ Plastic-Deformation and High-Strain-Rate- Induced Brittle Fracture}

Figures $1 \mathrm{a}$ and $\mathrm{lb}$ show typical spalled fracture surfaces in depleted uranium. Predominantly brittle fracture was observed in all the spalled uranium samples, with transgranular cracks for the 280 ppm purity sample, and with brittle intergranular cracks for the $38 \mathrm{ppm}$ purity samples. Some ductility is visible in the $280 \mathrm{ppm}$ purity uranium (Fig. 1a), and in the $38 \mathrm{ppm}$ purity uranium only large grains showed ductility in the form of ductile dimples (indicated in Fig. $1 b$ ).

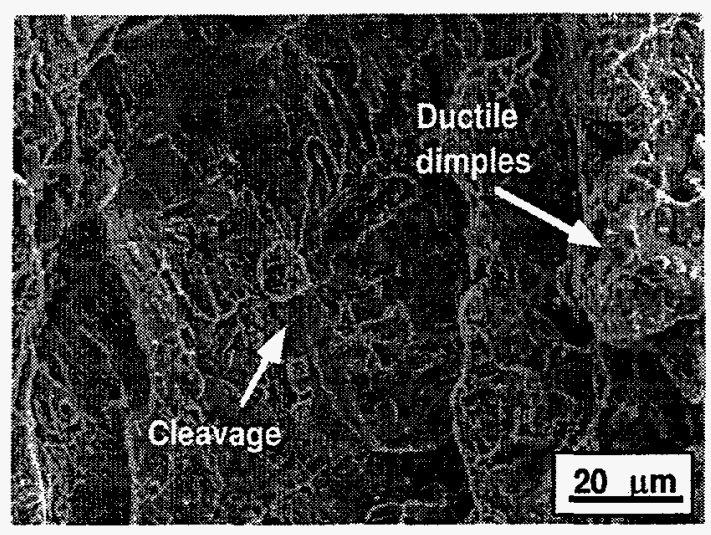

a

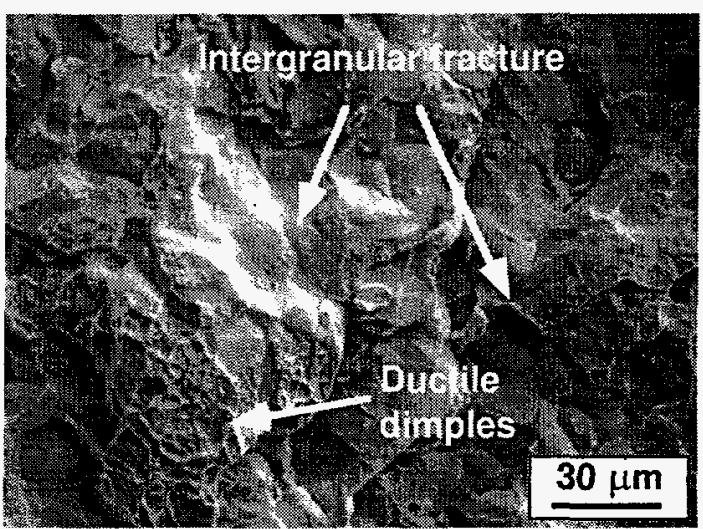

b

FIGURE 1. Fracture surfaces of depleted uranium spalled samples. (a) Depleted uranium with $280 \mathrm{ppm}$ carbon showing predominantly cleavage fracture surface. Depleted uranium with $38 \mathrm{ppm}$ carbon showing predominantly intergranular fracture. Both samples show some areas of ductile dimples. Both samples measured comparable spall strength of $-1.9 \mathrm{GPa}$.

Although $\alpha$ uranium is normally a ductile phase, the tests were performed at room temperature, which is close to the ductile-to-brittle transition temperature (DBTT) in uranium. The nature of the spall test, i.e. deformation at high pressure and high strain rate, contributes to the shift of the DBTT to higher temperatures when the strain rate dependence of the flow strength is taken 
into account [8]. In addition, the sample is subjected to high strain rate deformation and coincident hardening during the passage of the initial compressive shock wave. This deformation generates a high density of dislocations, and what is more important in the case of uranium, a large number of deformation twins; several twins variants are activated within each grain. Figures $2 \mathrm{a}$ and $2 \mathrm{~b}$ show the highly magnified microstructures of incipiently spalled samples for both purities of uranium.

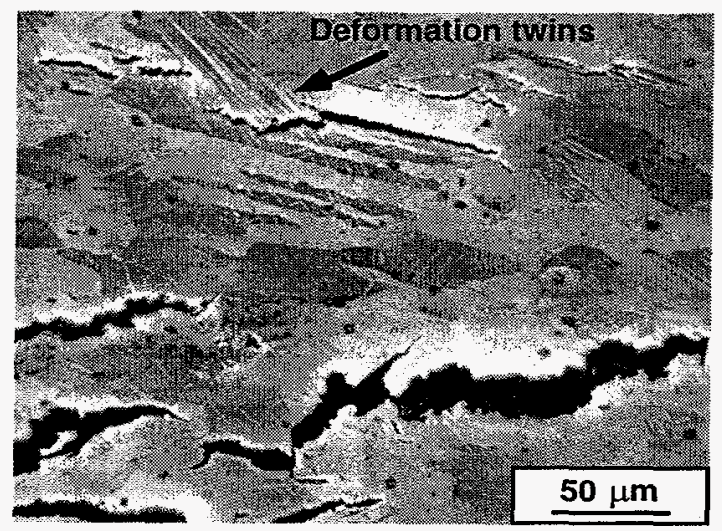

a

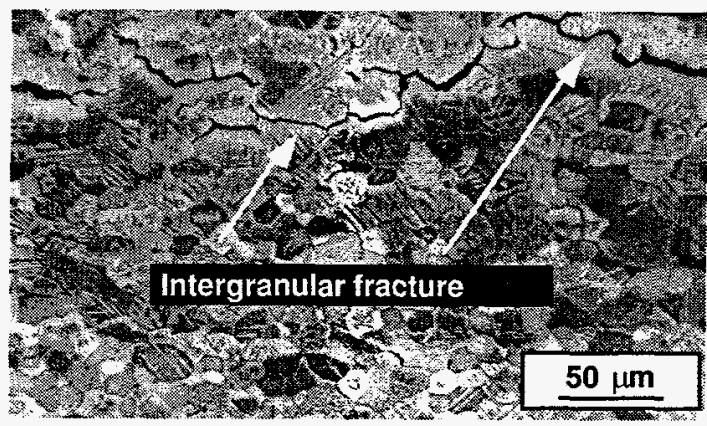

$b$

FIGURE 2. Cross section of depleted uranium samples incipiently spalled. (a) Depleted uranium with $280 \mathrm{ppm} \mathrm{C}$ showing large grains deformed under shock conditions with numerous twins and twin systems. Cracks in this sample are transgranular and frequently run along the twin/matrix interface. (b) Depleted uranium with $38 \mathrm{ppm} \mathrm{C}$ showing equiaxed grain structure, deformation twins within the grains, and cracks running along the grain boundaries.

It is evident that the cracks in the $38 \mathrm{ppm}$ purity uranium followed the grain boundaries (Fig. $2 \mathrm{~b}$ ), and the cracks in the $280 \mathrm{ppm}$ uranium are more correlated with the deformation twin systems developed in the sample during the shock.

The hydrostatic tension in the spall test is expected to aid microcrack nucleation. Workhardening processes are far more rapid in a spall test than in a tensile quasi-static test, which results in a substantial increase in the yield strength and flow stress. This increase makes the accommodation of plastic deformation at a crack tip more difficult and therefore favors intergranular or transgranular brittle fracture. In addition to the great number of deformation twins, twin intersections and twin-matrix interfaces can serve as preferred nucleation sites for sharp brittle cracks.

During quasi-static loading, DBT transition is dominated by the temperature dependence of the fracture stress. The hydrostatic pressure in a tensile test is about $1 / 3$ of the flow stress (tensile test $\Rightarrow 1 / 3 \leq-p / 2 \tau \leq 3)$, which is very small in comparison to the hydrostatic tension developed under spall conditions (spall test $\Rightarrow 7 \leq-\mathrm{p} / 2 \tau \leq 30$ ). In either case the hydrostatic pressure imposed on the sample during quasi-static or dynamic tests influences a shift in the ductile-to-brittle transition temperature. Figures $3 \mathrm{a}$ and $3 \mathrm{~b}$ schematically illustrate this phenomena by plotting the change in material yield strength with respect to temperature and the fracture stress.

The intersection of the fracture stress level with the yield stress curve marks the DBTT. Figure 3a shows an increase in fracture stress for a tensile quasi-static test with an imposed external compressive hydrostatic pressure.

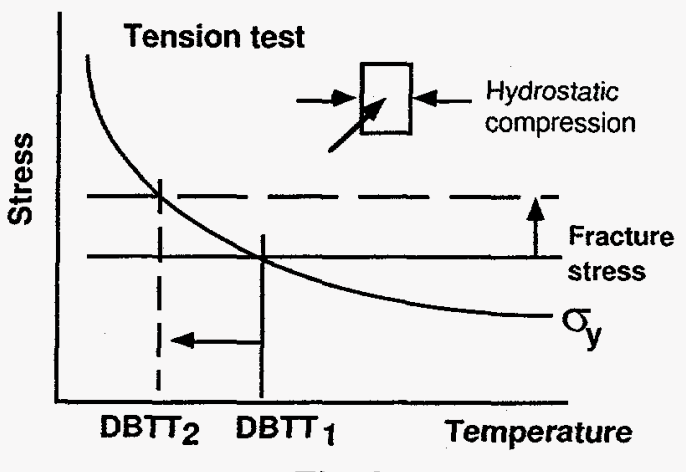

Fig. 3a 


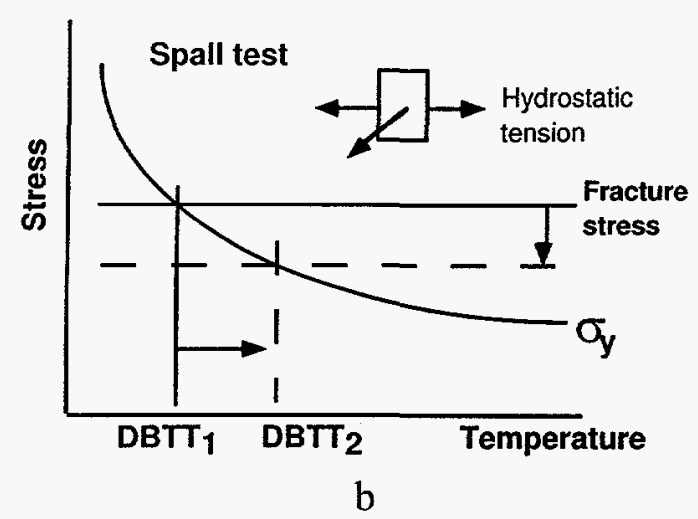

FIGURE 3. A schematic showing the DBT temperature shift resulting from the hydrostatic pressure. In the case of a tension test, compressive hydrostatic pressure imposed on a system shifts the fracture stress to a higher level and thereby the DBTT to a lower temperature (a). In a spall test an inherent to the test-very high tensile hydrostatic pressure-shifts the fracture stress to a lower level and thereby the DBTT to a higher temperature (b).

Figure $3 \mathrm{~b}$ schematically depicts a spall tensile stress state, with its inherent large tensile hydrostatic pressure, that decreases the fracture stress. In a tensile test, the compressive hydrostatic pressure shifts the DBTT to a lower temperature, while in a spall test, large tensile hydrostatic pressure shifts the DBTT to a higher temperature.

An example of the experimental evidence of this process is shown by Davidson [9] in magnesium tested under a quasi-static tensile stress state. A hydrostatic compression of $0.8 \mathrm{GPa}$ imposed on a $\mathrm{Mg}$ sample lowered the DBTT by over $230^{\circ} \mathrm{C}$ (from $175^{\circ} \mathrm{C}$ to $-55^{\circ} \mathrm{C}$ ) [9]. Likewise, the reverse is expected in a dynamic tensile spall test, where very high hydrostatic tension dominates the fracture process, lowering the fracture stress and therefore increasing the DBTT. This may explain the predominantly brittle fracture exhibited by depleted uranium under spall conditions.

The change in fracture mode from transgranular fracture for the $280 \mathrm{ppm} \mathrm{C}$ uranium (large grain) to intergranular fracture mode for $38 \mathrm{ppm}$ carbon content (small grain) uranium can be attributed to the possibility of hydrogen embrittlement in the latter. The amount of $2 \mathrm{ppm}$ of hydrogen (not outgassed) is sufficient to promote the grain boundary decohesion and therefore intergranular fracture.

\section{SUMMARY}

Two purities of depleted uranium samples were tested under spall conditions. The spalled samples showed predominantly brittle fracture: transgranular fracture for $280 \mathrm{ppm} \mathrm{C}$ uranium and intergranular fracture for $38 \mathrm{ppm} \mathrm{C}$ uranium. Deformation twinning was found to be the dominant form of deformation under spall conditions in the pure uranium samples. Both purities of uranium samples had a comparable spall strength of $-1.9 \mathrm{GPa}$. The high hydrostatic tension and very high strain rates inherent to spall testing are thught to increase the DBTT in pure uranium and thus promote brittle fracture.

\section{ACKNOWLEDGMENTS}

The authors would like to thank the Spall and Materials Damage Program Manager, Dean Preston of Los Alamos, for financial support. The work was done under the auspices of the US Department of Energy.

\section{REFERENCES}

[1] Eckelmeyer, K. H., in Uranium and Uranium Alloys, ASM International, Materials Park, Ohio, 1991.

[2] Zurek, A. K., Johnson, J. N., and Frantz, C. E., Journal de Physique, 49, (1988), pp. 269276.

[3] Thomason, P. F., in Ductile Fracture in Metals, Pergamon Press, Oxford, 1990.

[4] Johnson, J. N., J. of Applied Physics, 52, (1981), pp. 2812-2825.

[5] Curran, D. R., Seaman, L., and Shockey, D. A., Physics Reports, 147, (1987), pp. 253388.

[6] Dunn, P., private communication, 1997.

[7] Kelly, A., private communication, 1997.

[8] Zurek, A. K., Follansbee, P. S., and Hack, J., Metallurgical Transactions A, 21A, (1990), pp. 431-439.

[9] Davidson, T. E., Uy, J. C., and Lee, A. P., Acta Metallurgica, 14, (1966), pp. 937. 


\title{
MICROSTRUCTURE OF DEPLETED URANIUM UNDER UNIAXIAL STRAIN CONDITIONS
}

\author{
A. K. Zurek, J. D. Embury, A. Kelly, \\ W. R. Thissell, R. L., Gustavsen, \\ J. E. Vorthman, and R. S. Hixson \\ Los Alamos National Laboratory
}




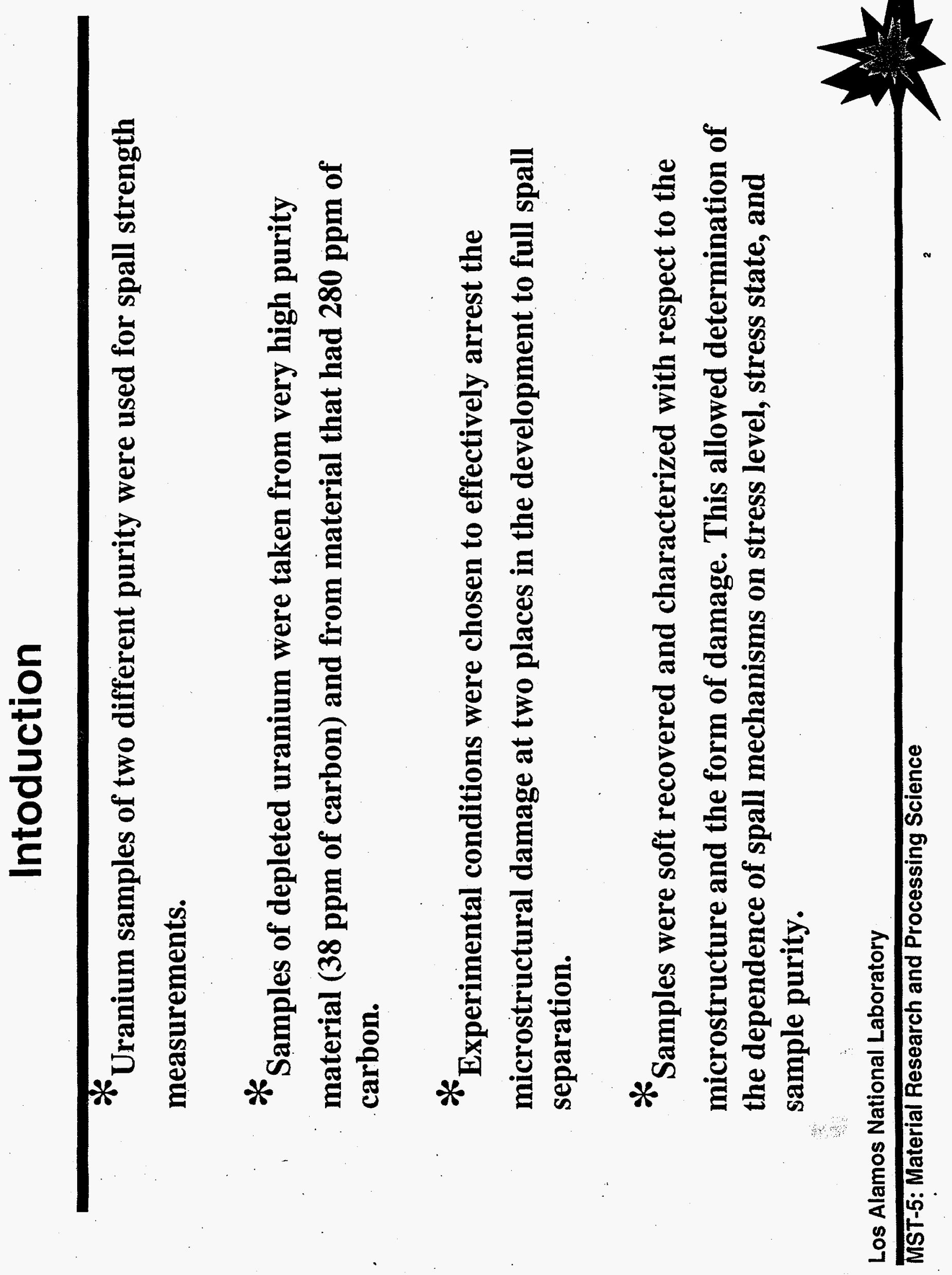




\section{Uranium-Carbon System}

\section{"Pure" uranium is a BINARY system}

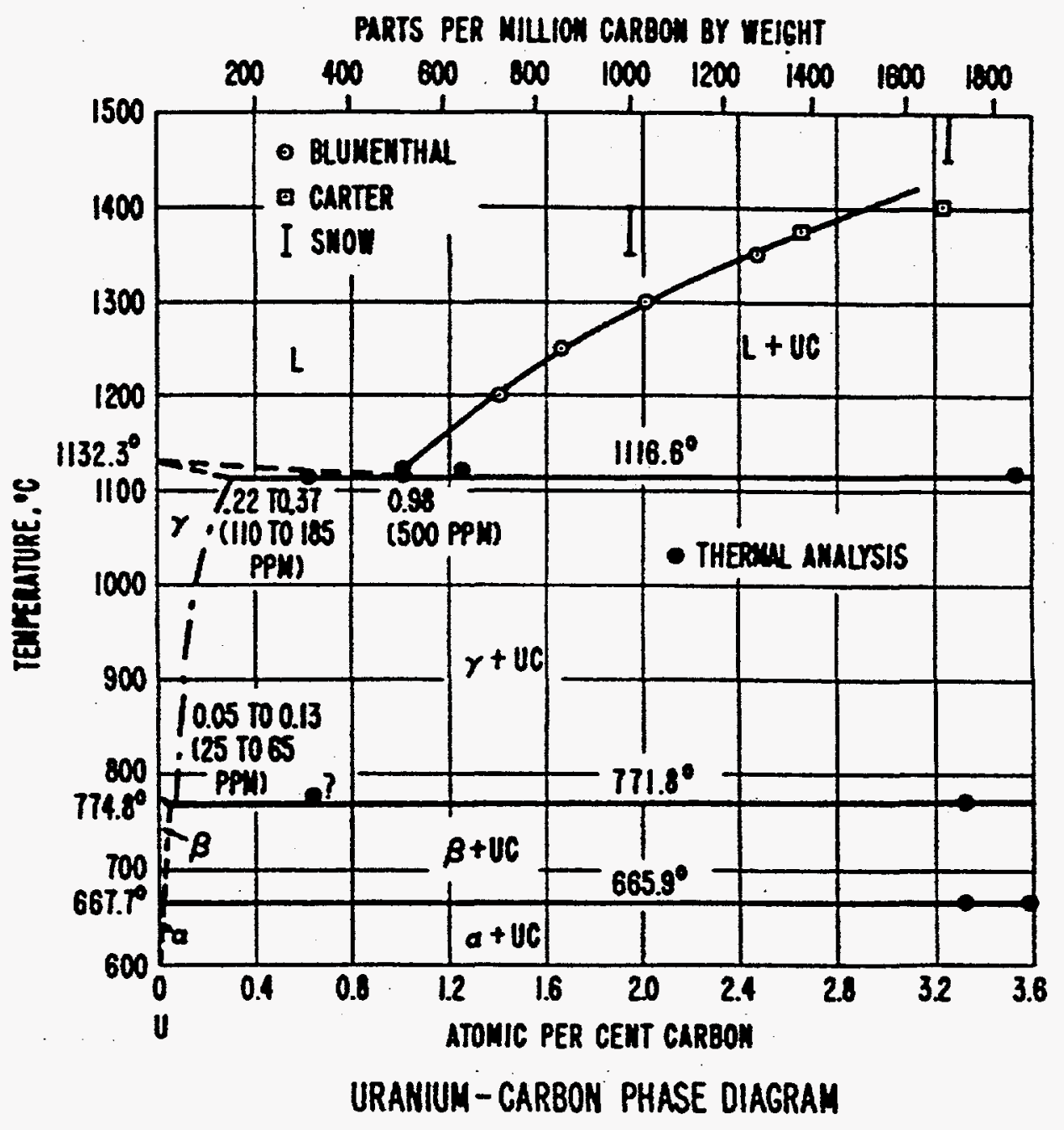

B. Blumenthal, J. of Nuclear Mat., 2 \#3, 197 (1960) 


\section{Uranium Properties vs. Temperature}

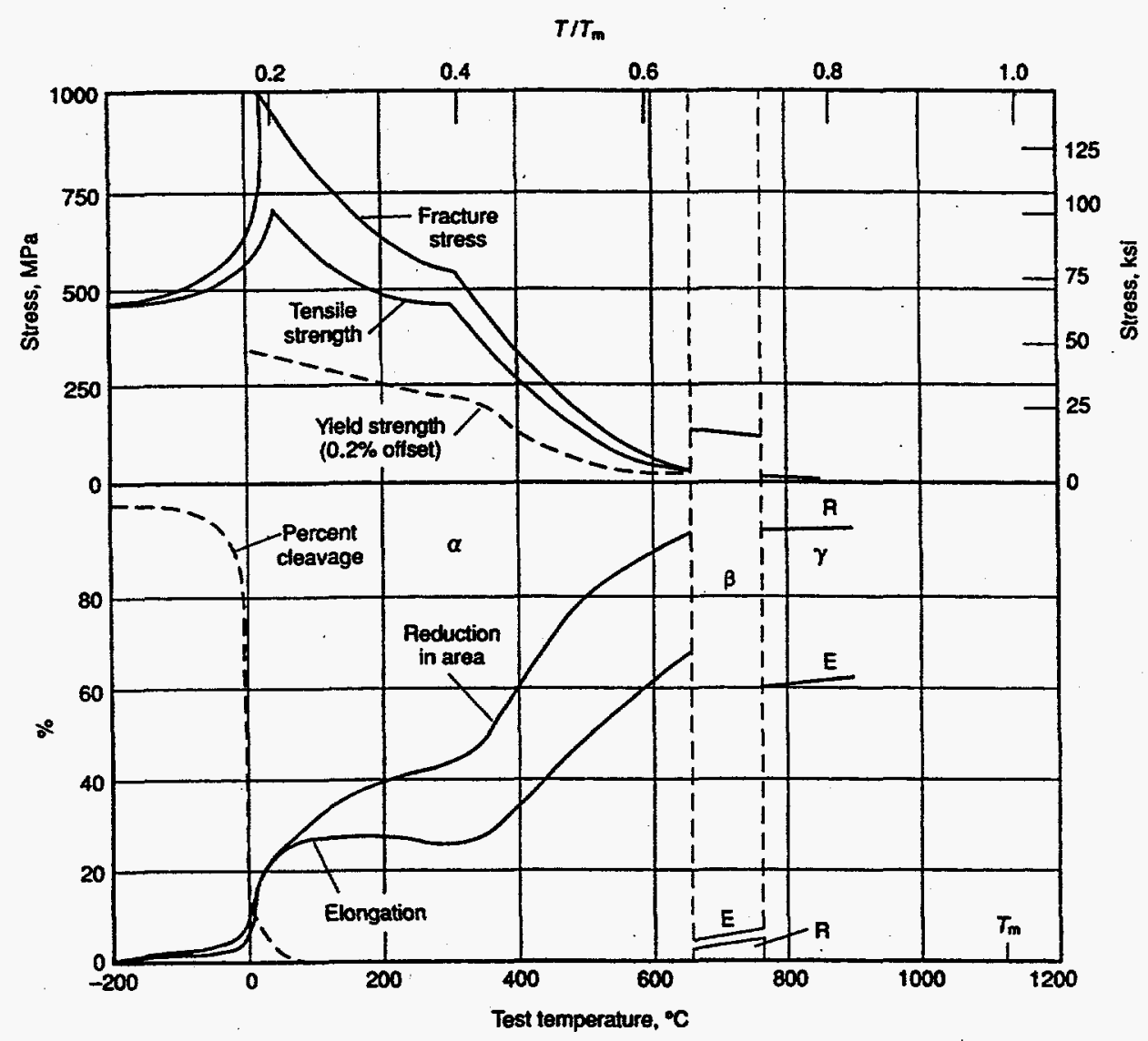

\section{Uranium displays unique properties as a function of temperature}

K.H. Eckelmeyer, ASM Handbook, vol. 2, pg. 670 (1991). 


\section{High Strain Rate Properties of Uranium}

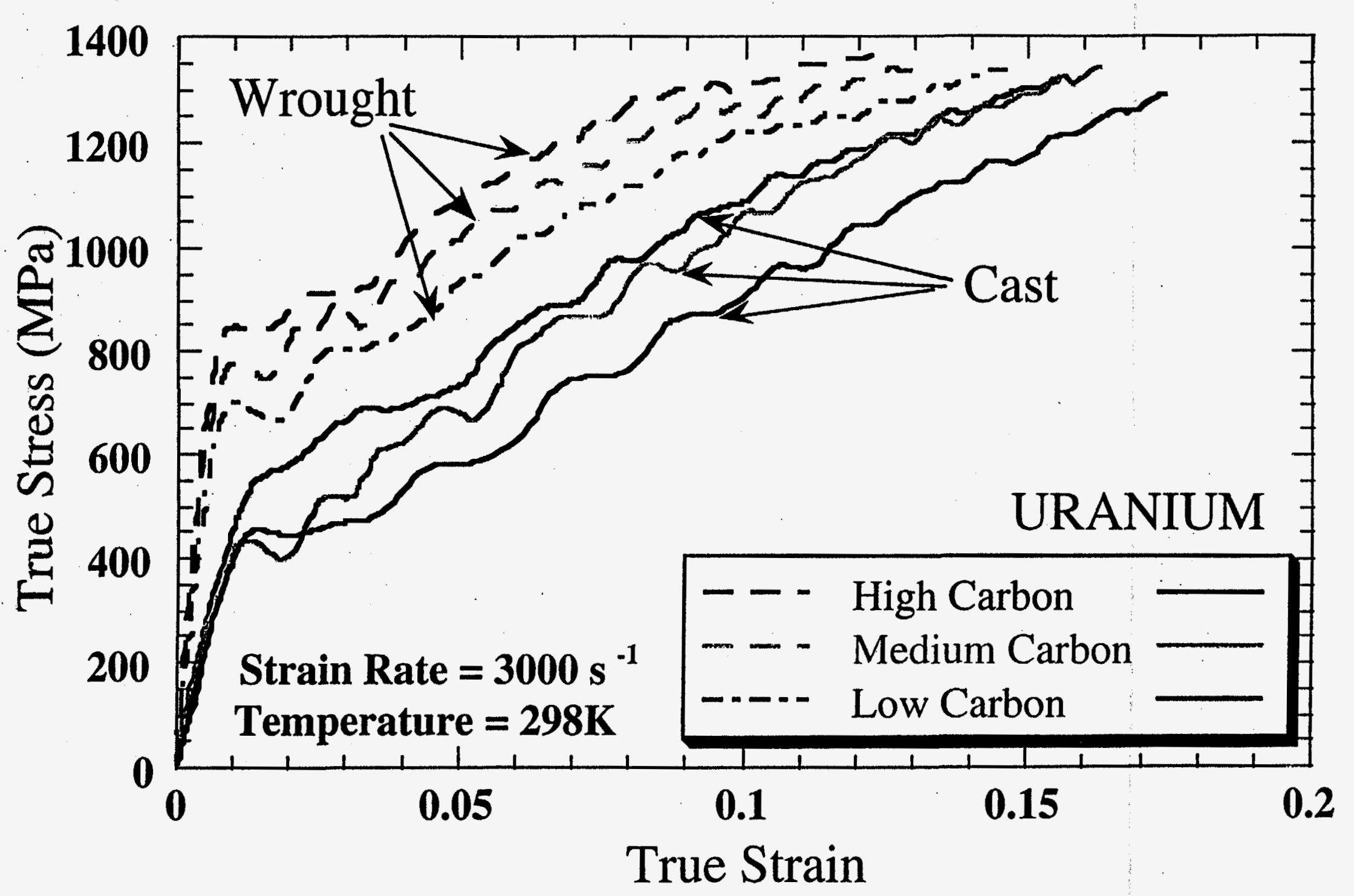

Los Alamos

Materials Science and Technology Division 


\section{$K_{\mathrm{IC}}$ dependece of strain rate and temperature}

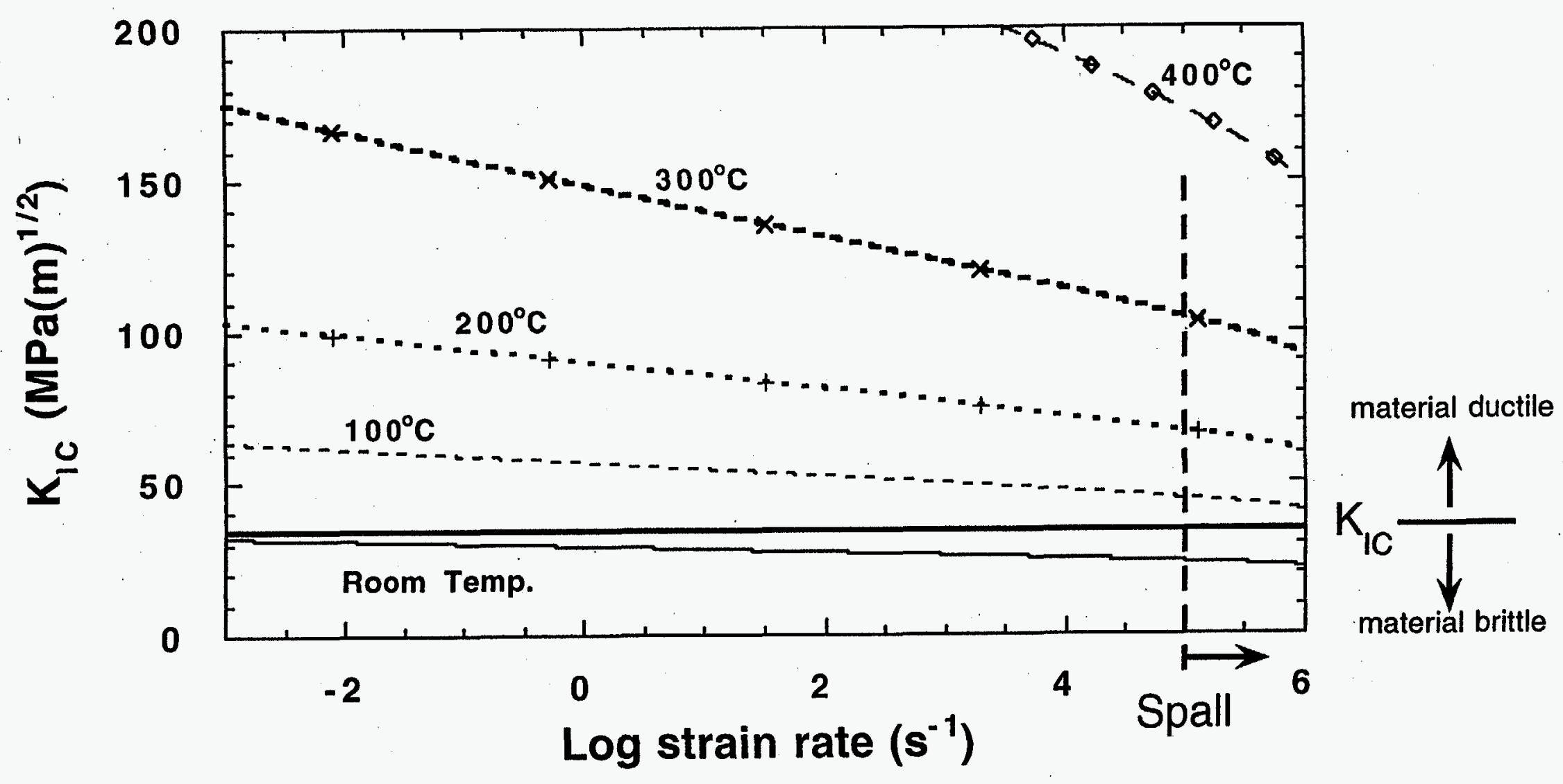




\section{$\mathrm{K}_{\mathrm{IC}}$ calculation}

This is only an estimate, because the mechanism of spall fracture differ from the plane strain Mode I fracture for which this analysis was developed (Lin et al.). The difference will lead to differences in the local stress distribution in the vicinity of the crack. In our case the formation of twins add to the process of more "brittle" behavior.

$$
\mathbf{K}_{\mathrm{IC}}=\mathbf{A} \frac{1}{\left\{\sigma_{\mathbf{a}}+\frac{\mu(\mathbf{T}) *\left(\hat{\sigma}-\sigma_{\mathbf{a}}\right)}{\mu_{0}}\left[1-\left(\frac{\mathbf{k T}}{\mathrm{g}_{0} \mu(\mathbf{T}) \mathbf{b}^{3}} \log \dot{\varepsilon}_{0} / \dot{\varepsilon}\right)^{2 / 3}\right]^{2}\right\}^{2}}
$$

$\hat{\sigma}=$ temperature dependent fracture stress

$\sigma_{\mathrm{a}}=$ atrermal stress (for uranium about $100 \mathrm{MPa}$ )

$\mu_{0}=91360(\mathrm{MPa})$, shear modulus

$\mu(\mathbf{T})=\mu_{0}-\frac{\mathbf{c}_{\mu}(=11.729 \mathrm{GPa})}{\exp \left(\frac{\mathbf{T}_{\mu}(=239 \mathrm{~K})}{\mathbf{T}}\right)-1}$

$\frac{\mathbf{K}}{\mathbf{b}^{3}}=0.5936$

$\mathrm{g}_{0}=1.6$

$\dot{\varepsilon}_{0}=10^{6}$

$\dot{\varepsilon}=$ strain rate 


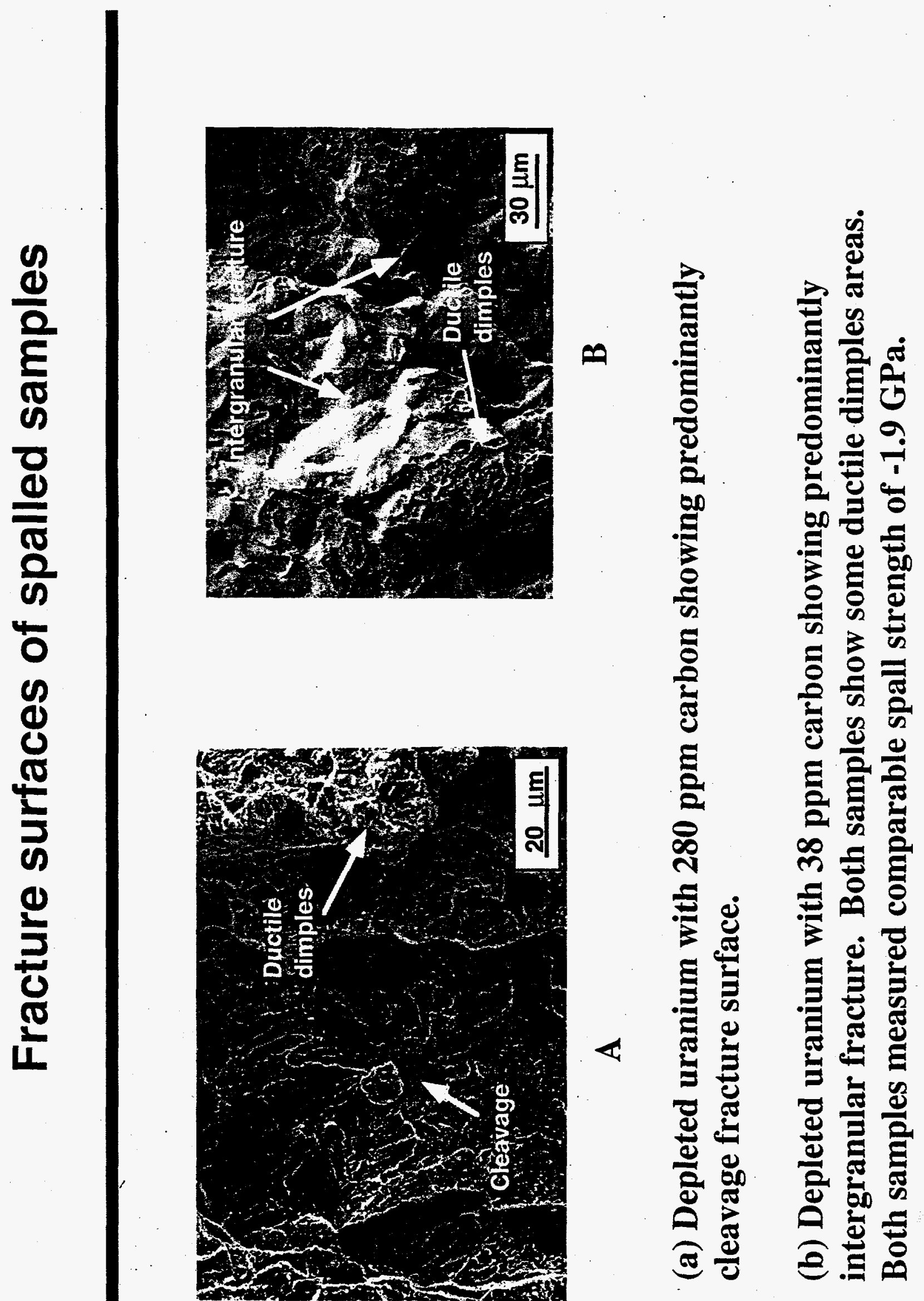



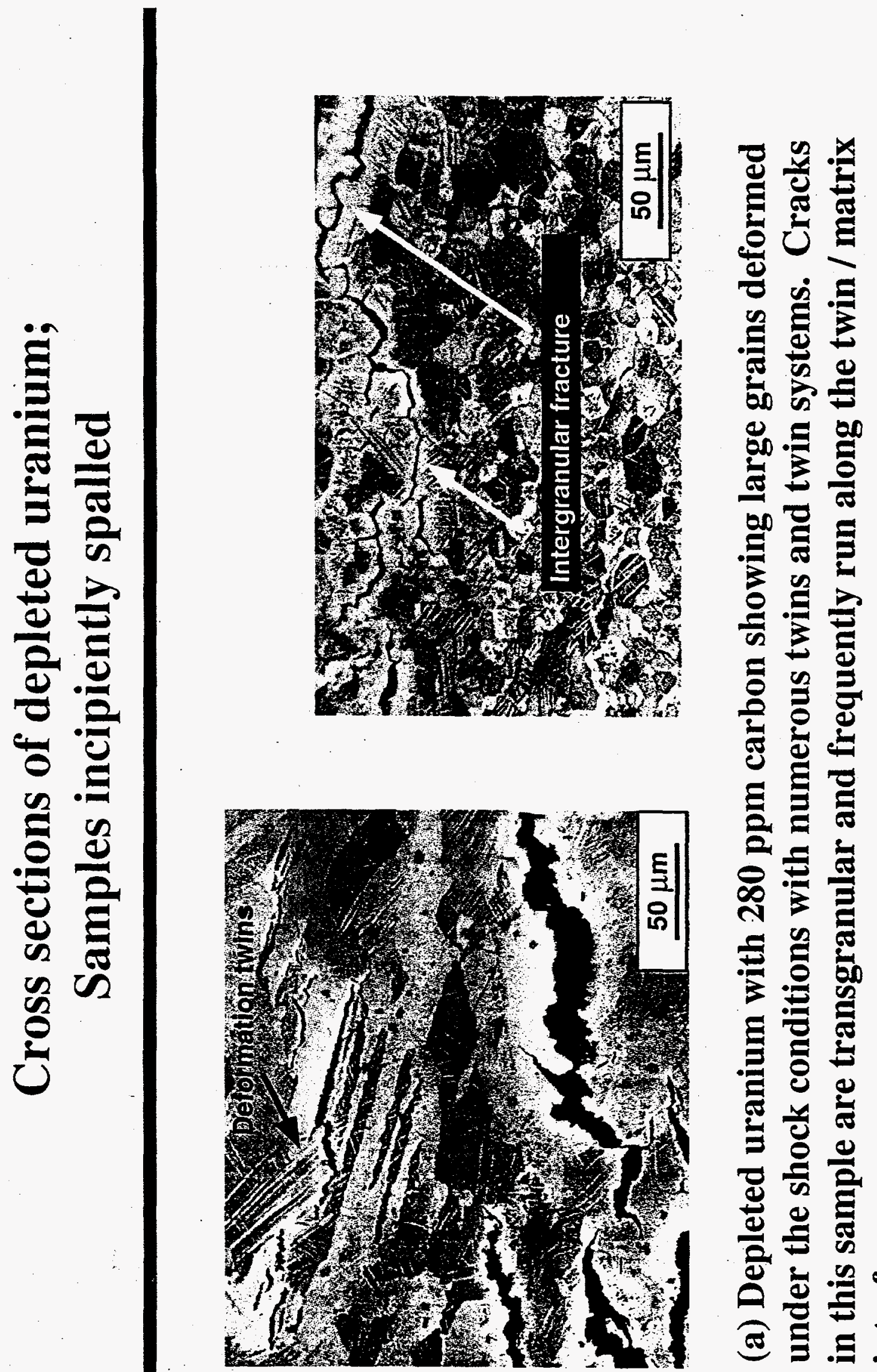

常
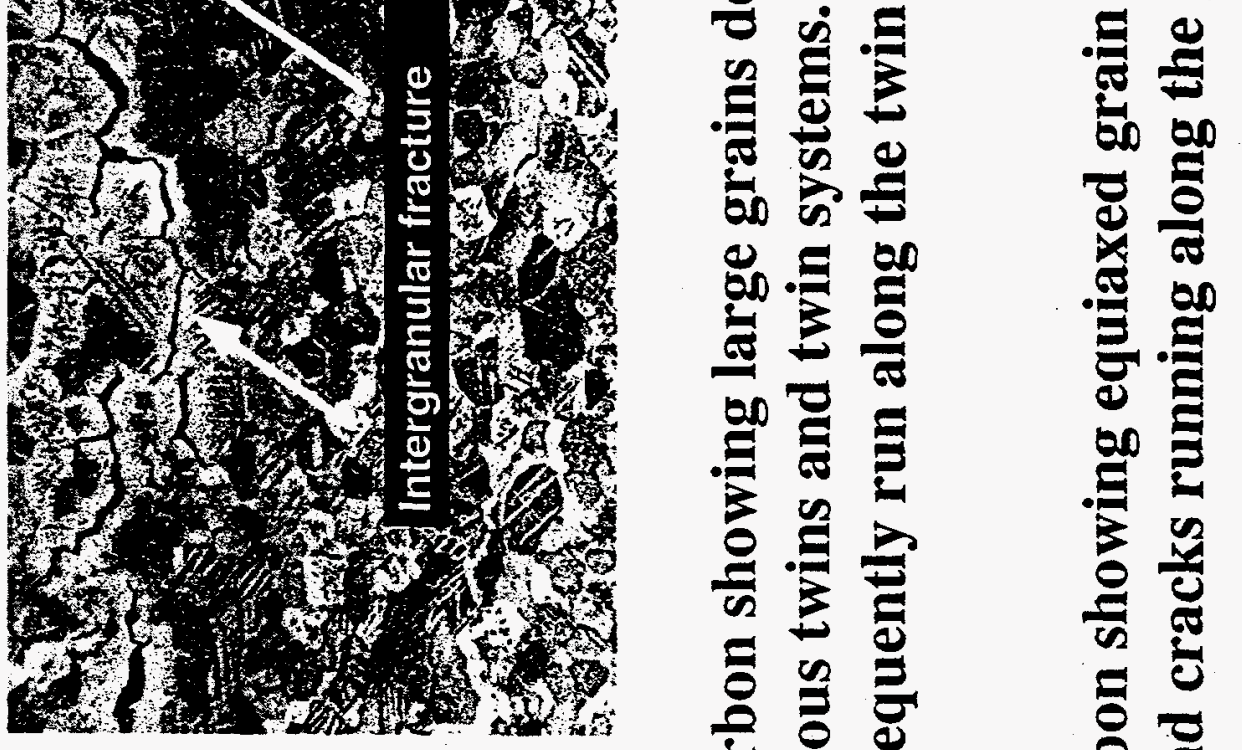

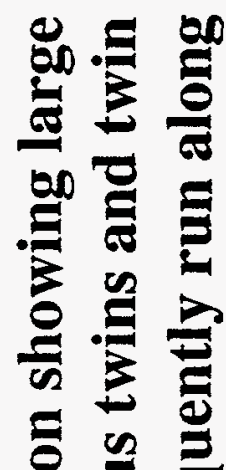

옹 ్ㅗㅇ

范

클

클

옹

串

돌

을

클 흘

$\Xi \Xi$

를

플

$\exists \circlearrowright$

월 흘

氖

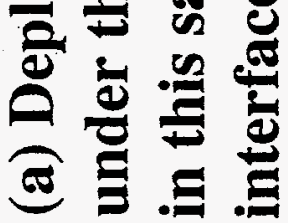

马्ष

番

호ㅇㅡㅗ

일

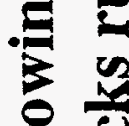

암

.

을

J

E.

을

$\infty$ 央

ल

$\Xi$

要

E

当

当

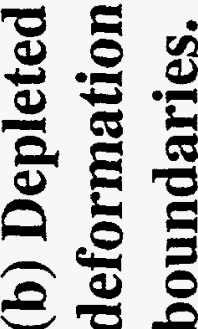




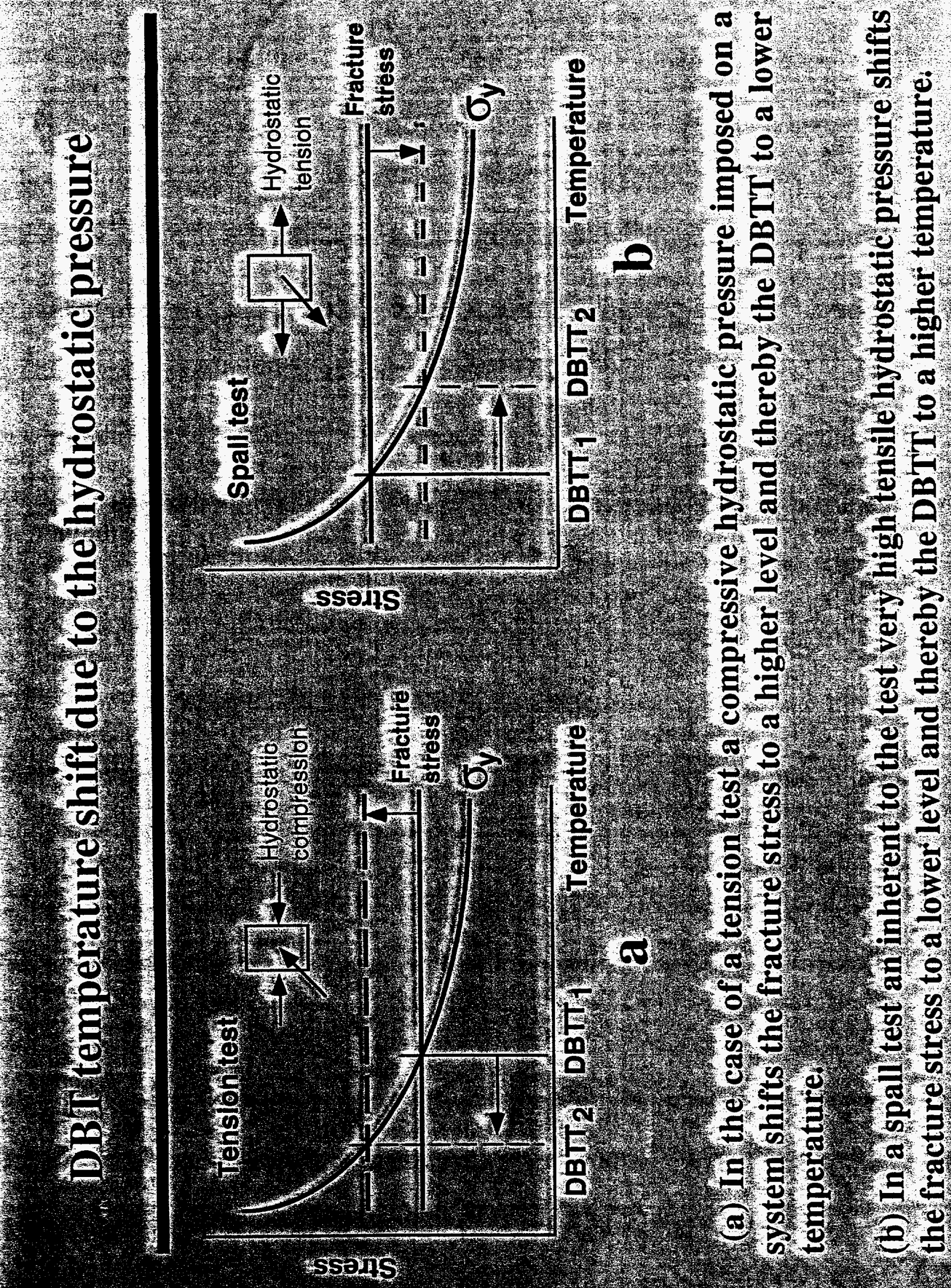

